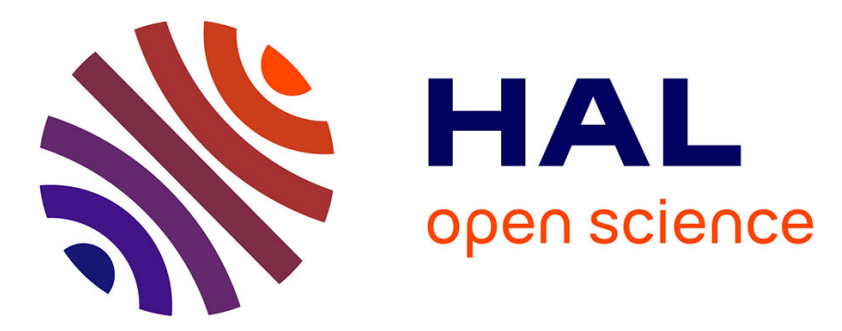

\title{
Material and Energy Beneficiation of the Automobile Shredder Residues
}

Nour-Eddine Menad, N. Kanari, Sylvain Guignot, Frédéric Diot, Lev Filippov, Fabien Thomas, Jacques Yvon

\section{- To cite this version:}

Nour-Eddine Menad, N. Kanari, Sylvain Guignot, Frédéric Diot, Lev Filippov, et al.. Material and Energy Beneficiation of the Automobile Shredder Residues. Rewas 2013: Enabling material resources sustainability, Mar 2013, San Antonio, United States. pp.89-99, 10.1002/9781118679401.ch10 . hal01017127

\section{HAL Id: hal-01017127 https://hal-brgm.archives-ouvertes.fr/hal-01017127}

Submitted on 1 Jul 2014

HAL is a multi-disciplinary open access archive for the deposit and dissemination of scientific research documents, whether they are published or not. The documents may come from teaching and research institutions in France or abroad, or from public or private research centers.
L'archive ouverte pluridisciplinaire HAL, est destinée au dépôt et à la diffusion de documents scientifiques de niveau recherche, publiés ou non, émanant des établissements d'enseignement et de recherche français ou étrangers, des laboratoires publics ou privés. 


\title{
MATERIAL AND ENERGY BENEFICIATION OF THE AUTOMOBILE SHREDDER RESIDUES
}

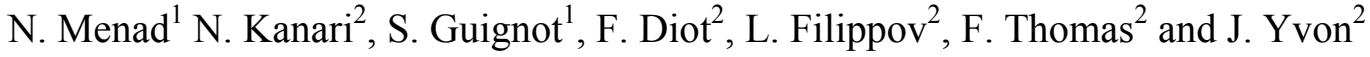 \\ ${ }^{1}$ BRGM - D3E/DMP, 3, avenue Claude Guillemin - BP 36009, 45060 Orléans cedex 02, France. \\ ${ }^{2}$ Laboratoire Environnement et Minéralurgie, UMR 7569 CNRS, Nancy-University, ENSG, BP \\ 40, 54501 Vandœuvre-lès-Nancy, France.
}

Keywords: automobile shredder residues, thermal beneficiation, iron oxides reduction

\begin{abstract}
Although vehicles represent a main key of our modern society, they affect our environment via the energy and resource consumption, waste generation during their manufacturing as well as greenhouse gas emissions all along their use. Further, hazardous residues are produced at the end-of-life vehicles "ELV". After collection and dismantling, the remainders of the ELV are directed to shredding operator followed by a series of mechanical and physical separations in order to recover the ferrous and non-ferrous metals. The residue of the shredding process, called automobile shredder residue "ASR" represents about 20-25\% of the ELV. The ASR, while toxic enough to be classified as hazardous waste, could be considered as material and energy sources.

The present study deals with the possibility of material and energy beneficiation of the ASR by its use in the metallurgical units. ASR samples from an European automobile shredder company were collected and subjected to the physical separation process followed by a thermodynamic approach and isothermal batch tests to assess the reducing performance and energy capacity of the ASR hydrocarbon matter. Particular attention was devoted to the behavior of several residual and tramp elements $(\mathrm{Cl}, \mathrm{Pb}, \mathrm{Cu}, \mathrm{Zn})$ affecting the metallurgical process and the product quality. Results showed that physical operations (screening, attrition, dry low intensity magnetic separation) lead to a selective extraction of the mineral part of the ASR which can be directed to the blast furnace unit. Direct reduction of hematite by the plastics contained in the ASR was obtained at $1000-1050{ }^{\circ} \mathrm{C}$ resulting into multistage steps of $\mathrm{Fe}_{2} \mathrm{O}_{3}$ converting into metallic iron. Multi-parametric analysis of the results suggests that the purified ASR can partially substitute raw materials used in pig iron and steel production.
\end{abstract}

\section{Introduction}

Vehicles represent a main key of our modern society and their number in use is increasing from year to year, reaching, in 2010, about one billion cars and light trucks on world's roads [1]. However, vehicles affect the environment through their entire life cycle. This environmental impact relates to the energy and resource consumption, waste generation during their manufacturing as well as greenhouse gas emissions all along their use. Further, hazardous residues are produced at the End-of-Life Vehicles "ELV". 11 million vehicles are annually discarded in the European Union, resulting in about $9 \mathrm{Mt}$ of wastes that have to be disposed of [2]. Current European state of practice for spent cars processing falls into a manual depollution followed by the shredding of the cars hulks, which generates 2 to 2.5 million tons of Automotive Shredder Residues (ASR) each year [3]. Without further treatments, this residual stream is mainly landfilled or sent to municipal incinerators [4]. European legislation will impose a 
recycling rate greater than $95 \%$ of the car initial weight by 2015 , resulting in less than $5 \%$ of waste discharge [5]. Although, the ASR is reactive enough to be classified as hazardous waste, it could be considered as a source of energy and reducing agent since it contains more than $70 \%$ in combustible hydrocarbon matter (Figure 1), especially plastics. Note that the shredder companies use, besides ELV, other materials (e.g. plastics from discarded electric and electronic assemblies) in the shredding process leading often to a heterogeneous ASR depending on the input materials. Meeting the legal requirements by addressing the issue of ASR has led to the development of several Post-Shredder industrial lines of treatments [4], in which a fluff fraction is recovered by vacuuming ASR lighter components during shredding. Residual metals and plastic-rich fractions are then extracted from this fluff by means of magnetic, eddy current and sequences of sink-float separations.

Besides being marketed anew, recovered plastics can be valued as a relevant additive to the pulverized coal injected through blast furnace tuyeres [6]. In addition, considering that iron content in ASR can mount up to $18(\%)_{\mathrm{wt}}$ of the light fraction [7], residual mineral fractions might also be used as part of the ore feedstock in metallurgical furnaces, provided further enrichments are performed to curb specific tramp elements. For instance, upon combustion, materials containing chlorine generate gas which is corrosive for the furnace and the dusts removal post-treatments [8]. $\mathrm{K}_{2} \mathrm{O}$ can deposit into coke and sinter porous structures and weakens their Reduction Degradation Index (RDI). Copper is related to surface cracking of steels during hot rolling process. $\mathrm{Sb}, \mathrm{Sn}$ and As accentuate this negative effect by segregating at grain boundaries during coiling in the hot strip mill, thus reducing the grain cohesion and thereby favoring embrittlement. This segregation is higher in steel containing $\mathrm{Ni}, \mathrm{Mn}$ and $\mathrm{Cr}$. Lastly, gaseous zinc can condense onto the blast furnaces inner walls, favoring scabs that modify the furnace flow configuration.

Despite such considerations on the chemical composition of plastic and mineral fractions generated from Post-Shredder industrial lines of treatments, few studies consider the design of a separation process which would open the way for a Blast Furnace (BF) injection. The present paper addresses this issue by focusing on 2 plastic fractions and 2 mineral fractions sampled on an industrial Post Shredder line of ASR treatment, so as to dispose of representative composition data. The separation processes associate sieving, gravity separation and low intensity magnetic separation. The separation efficiency is discussed in line with the chemical composition of the various outlets obtained. For the most interesting outlets, their use in a BF is assessed through a mass balance model of the tramp elements inside the furnace, with an attention paid to the effect on the pig iron specifications and the steel quality. 


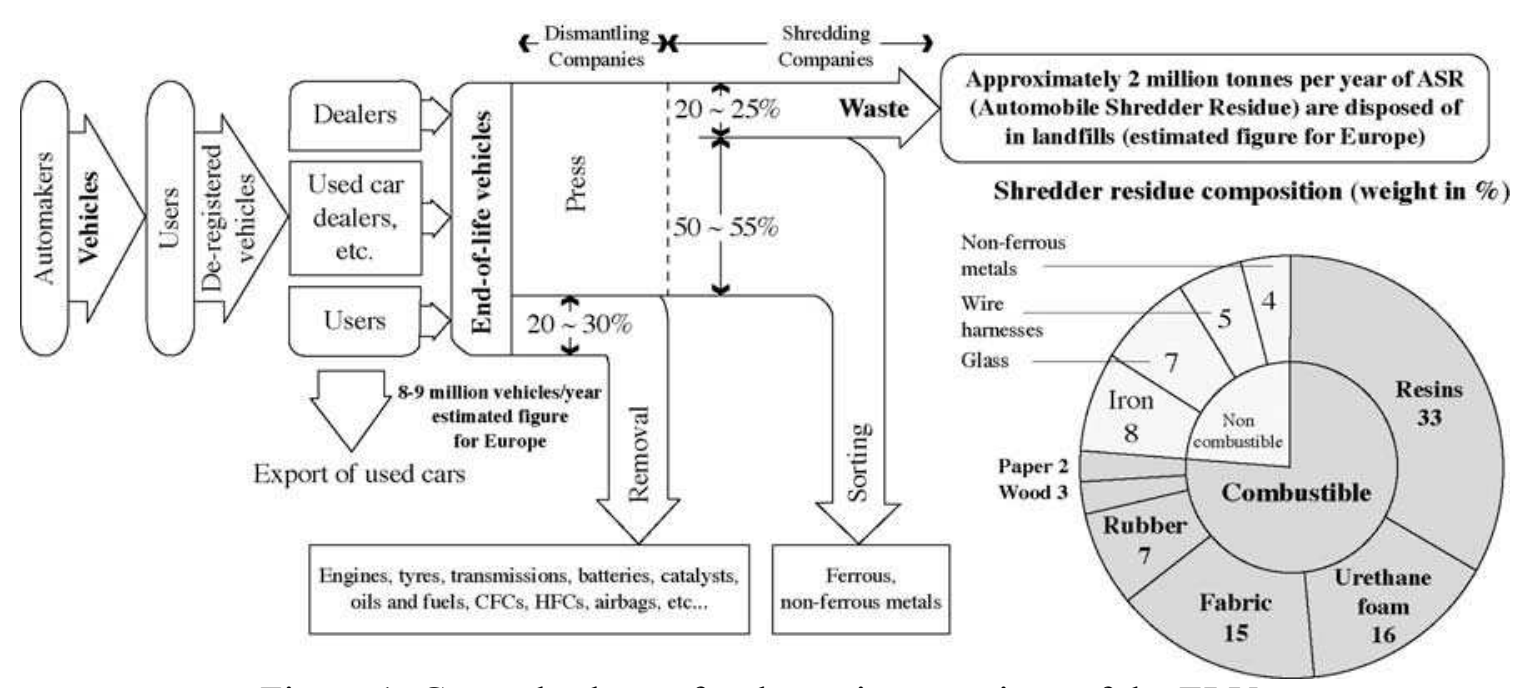

Figure 1: General scheme for the main operations of the ELV.

\section{Materials}

Four ASR samples were supplied by an European automobile shredder company and two of them, composed essentially of the wasted plastics. They are separated by sink float process and they are classified as Light Fraction "LF" and Dense Fraction "DF". The carbon content of the LF is about $66.8 \%$ whilst that of the DF is $42.1 \%$. Chlorine is almost concentrated in the DF $(6.8 \% \mathrm{Cl})$ indicating the presence of the PVC and of certain rubbers. Tramp elements $(\mathrm{Pb}, \mathrm{Zn} .$. as well as calcium are also found mostly in the DF. The other two samples were sampled from successive dry low intensity magnetic separations and called mineral fractions (MF\#1 and MF\#1). These fractions contain $36.8 \%$ and $19.4 \%$ of iron oxides respectively. Chlorine is almost the same in both fractions $(0.3 \%)$. The carbon content of the MF\#1 is approximately $8 \%$ whilst that of the MF\#2 is $10.5 \%$. The tramp elements $(\mathrm{Pb}, \mathrm{Zn} . .$.$) as well as \mathrm{CaO}$ and $\mathrm{SiO} 2$ are found in both fractions.

\section{Methods}

Two PVC samples were used for this investigation of the plastic fractions. The first sample is wasted PVC and it is noted as PVC-1. The second sample is pure chemical grade PVC and is called PVC-2. Iron oxide, subjected to reduction, is high purity hematite $\left(\mathrm{Fe}_{2} \mathrm{O}_{3}\right)$. Thermodynamic approach using HSC chemistry was considered for selective removal of tramp elements $(\mathrm{Pb}, \mathrm{Cu}, \mathrm{Zn} \ldots)$ via chloride formation \& volatilization and for hematite reduction. Mixtures of ASR and/or PVC samples with hematite were conditioned as pellets by using kaolin clay as useful bonding and plasticizing agent. Obtained pellets were dried in an oven at $70{ }^{\circ} \mathrm{C}$ before thermal treatment and different analysis tests. The thermal behaviors of the individual samples and their mixtures were checked in horizontal experimental set-up including a static electrical furnace. Most of the tests were performed under air atmosphere for the treatment of the ASR and PVC alone. The thermal reduction of hematite containing mixtures was performed without gas circulation and/or under a low flow rate of air. Raw samples and solid reaction products were examined by scanning electron microscopy coupled with energy dispersive spectroscopy (SEM-EDS), X-ray diffraction (XRD) and infrared (DRIFTS) spectroscopy.

The two mineral fractions MF\#1 and MF\#2 were subjected to physical separations, where. Sorting operations such as grinding, screening, attrition, and magnetic separation were used in this investigation. Two-stage sieving were performed, first on a rotating, perforated drum loaded 
with steel bars (cut $2 \mathrm{~mm}$ ), then manually (cut $100 \square \mathrm{m}$ ) on the $-2 \mathrm{~mm}$ fraction, resulting in three sub-fractions: $-100 \square \mathrm{m},+100 \square \mathrm{m}$ and $+2 \mathrm{~mm}$. Dry Low Intensity Magnetic Separation was performed on a two-staged Lenoir Rollmag 500-2 separator. Two separations were successively performed. The first gave two fractions composed of ferromagnetic or weakly magnetic compounds. Each of these fractions was separated again, and the two ferromagnetic parts were mixed together, as well as the two weakly magnetic parts. Attrition was carried out on the materials in pulp $\left(65(\%)_{\mathrm{wt}}\right)$ using a Cylab-1 $(2125 \mathrm{rpm}) .5$ cycles of 1 min each were performed. The resulting fractions were dried in an oven $\left(105^{\circ} \mathrm{C}\right.$ during $\left.24 \mathrm{~h}\right)$. Using composition data, mass balances were carried out at a blast furnace scale for each tramp element.

\section{Results and discussion}

\section{Thermal Behavior of LF and DF Samples in Air Atmosphere}

The investigation of reactivity of ASR and PVC samples was performed between $225{ }^{\circ} \mathrm{C}$ and $900{ }^{\circ} \mathrm{C}$ under air atmosphere. Results are shown in Figure 2 as the evolution of the percent weight loss $(\% \mathrm{WL})$ of the samples as a function of the temperature
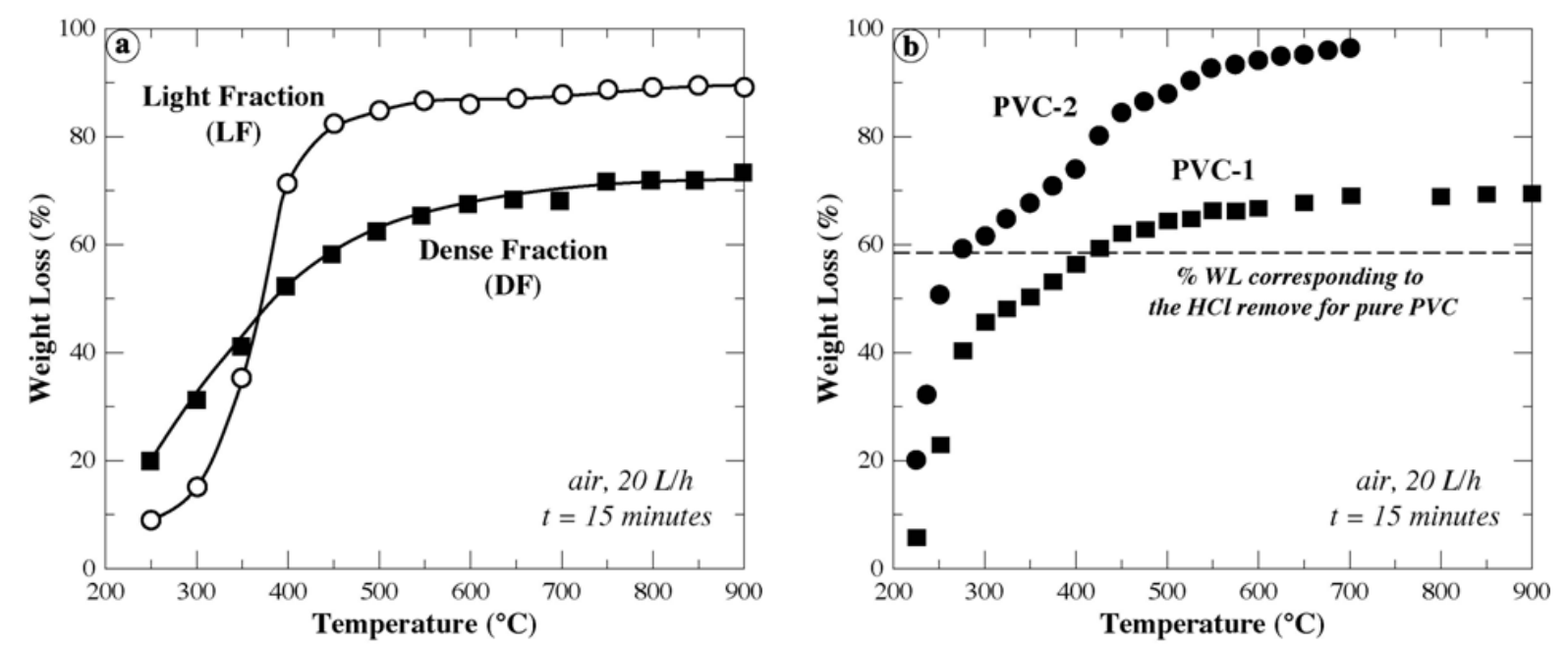

Figure 2: Behavior of ASR (a) and PVC (b) samples in air between 200 and $900^{\circ} \mathrm{C}[10]$.

From Figure 2 (a), it can be seen a very rapid weight loss of both plastic fractions (LF and DF) at temperatures lower than $600^{\circ} \mathrm{C}$. This is due to the combustion of the organic matter contained. Scanning electron microscopy (SEM) and X-ray diffraction (XRD) reveal the presence of mineral compounds $(\mathrm{Si}, \mathrm{Ca}, \mathrm{Mg}, \mathrm{Al} \ldots)$ in the residues obtained at higher temperatures. A rough examination of the \% WL curves for PVC samples (Figure. 2-b) suggests that at least two phenomena should be distinguished at temperatures lower and higher than $300{ }^{\circ} \mathrm{C}$. The first phenomenon could be attributed to a complete (PVC-2) or partial (PVC-1) removal of chlorine. The \% WL observed at temperatures higher than $300{ }^{\circ} \mathrm{C}$ may indicate the reaction of the hydrocarbons with oxygen giving carbon oxides and water vapor as final reaction products. Detailed analysis for de-chlorination of both PVC samples was given early [9] [10]. However, these results suggest a high reactivity of all studied samples at relatively low temperatures.

The results of the analytical techniques (SEM, XRD, and IR) on treatment products have been at the base of deductions on the thermal behavior of PVC samples. The IR spectra of the PVC-1 Treated at different temperatures are grouped in Figure 3. It can be observed that between 2950 and $2840 \mathrm{~cm}^{-1}$ some signals characteristics of elongation $\mathrm{C}-\mathrm{H}$ of $\mathrm{CH}_{\mathrm{x}}$ groups. The intensity of 
these bands decreases with increasing temperature to 'disappear' for $\mathrm{T} \geq 600^{\circ} \mathrm{C}$. This is consistent with the data given in Figure 2. The presence of carbonates is observed in all the Spectra up to $900^{\circ}$ C. XRD confirms the presence of calcite in the initial PVC and heat treatment products

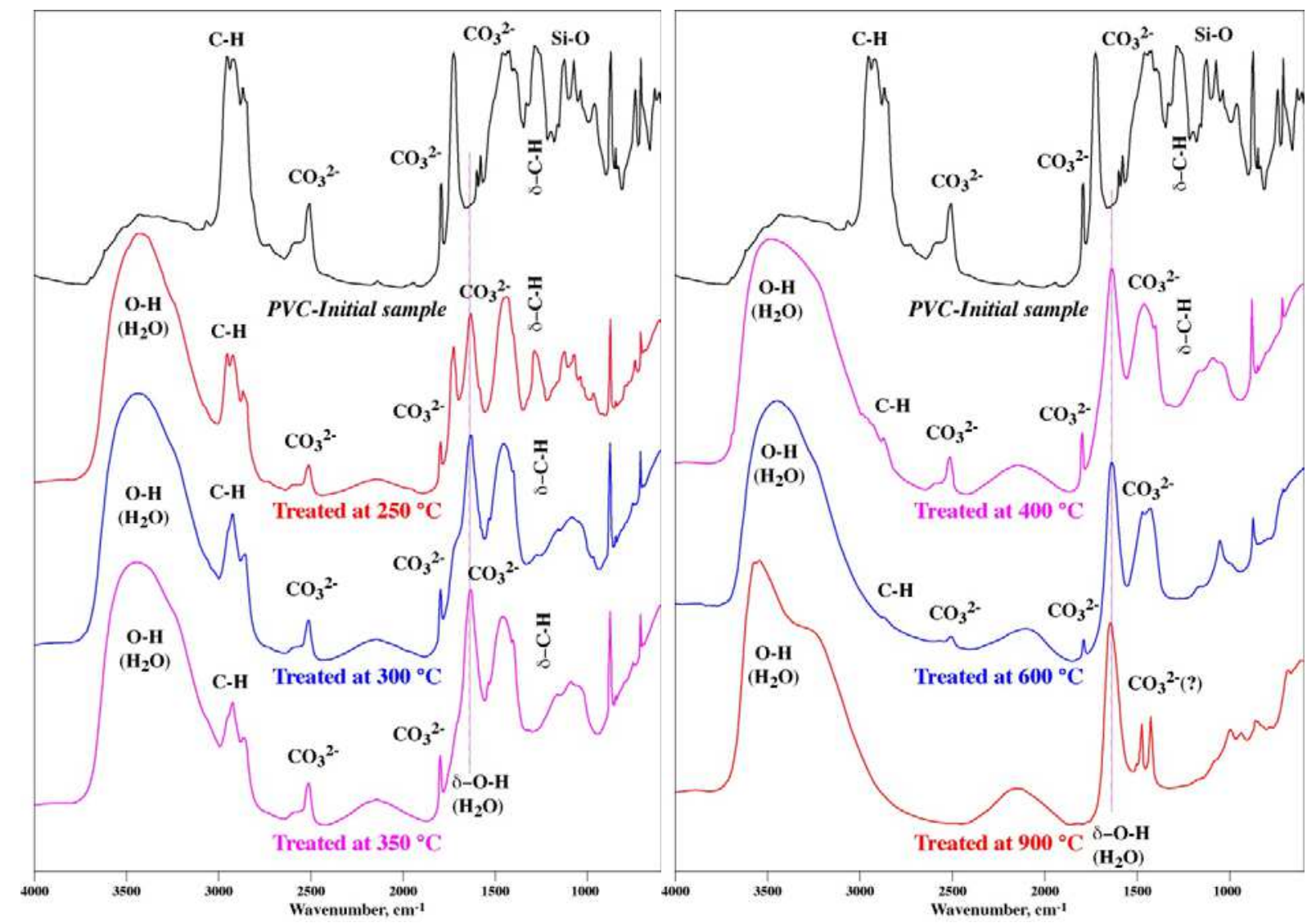

Figure 3 - IR Spectra after treatment of PVC-1 between 250 and $900{ }^{\circ} \mathrm{C}$.

$\underline{\text { Reduction of Hematite by PVC and ASR }}$

The following mixtures were tested in view of iron oxide reduction
1. $35 \% \mathrm{LF}+35 \%$ hematite $+30 \%$ clay,
2. $(35 \%$ PVC $-1+35 \%$ hematite $+30 \%$ clay,
3. $50 \%$ PVC- $1+50 \%$ hematite

The results show that the chlorine was almost removed at about $275^{\circ} \mathrm{C}$ from $\mathrm{PVC}$, and then, the mixtures were de-chlorinated at $300{ }^{\circ} \mathrm{C}$ for 30 minutes. Subsequently, free of chlorine pellets were heated from 600 to $1050{ }^{\circ} \mathrm{C}$ for 30 minutes. Several tests were also carried out at $1025{ }^{\circ} \mathrm{C}$ with a residence time from 7.5 to 240 minutes. Obtained experimental and analytical results related to the reduction of iron oxides are described below. They are compared with the wellknown Chaudron and Boudouard diagrams drawn in Figure 4. 


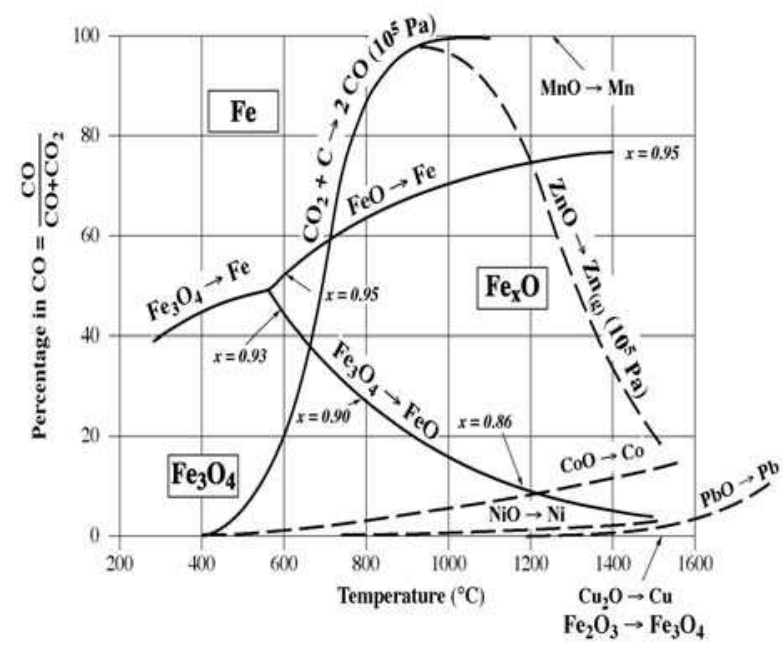

Figure 4: Equilibrium diagram of some metallic oxides reduction by carbon monoxide.

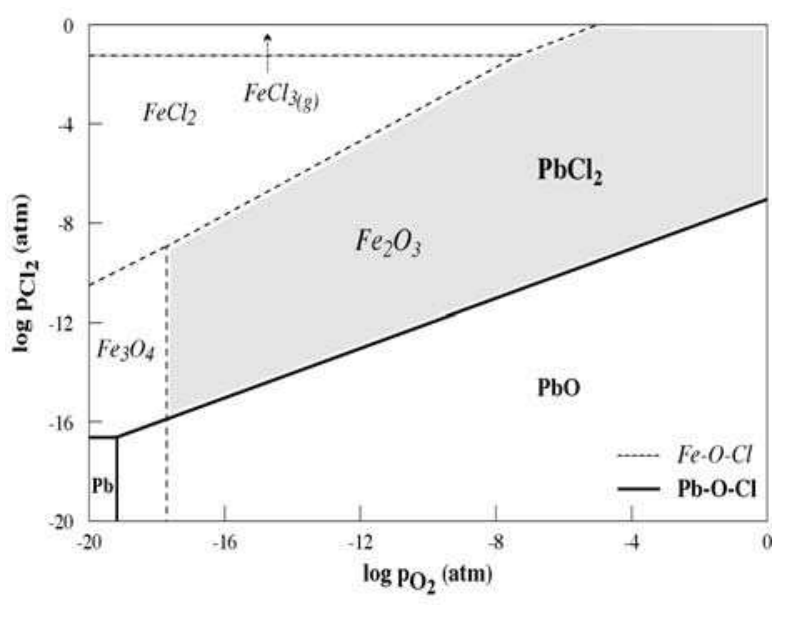

Figure 5: Phase stability diagram of $(\mathrm{Fe}, \mathrm{Pb})-$ $\mathrm{O}-\mathrm{Cl}$ systems at $500{ }^{\circ} \mathrm{C}$

The following points summarize the results obtained from the reduction of hematite by plastics (PVC and ASR), mechanisms and the reduction steps.

1. The reduction of hematite to magnetite by hydrocarbon of $\mathrm{PVC}$ starts at $300^{\circ} \mathrm{C}$, even in the presence of air (as shown in Figure 3, the reduction of $\mathrm{Fe}_{2} \mathrm{O}_{3}-\mathrm{Fe}_{3} \mathrm{O}_{4}$ is possible for Low CO concentration).

2. Metallic iron is obtained during the direct reduction of hematite at $1000^{\circ} \mathrm{C}$ which is confirmed by XRD and SEM analyses. In addition, the crystallized fayalite $\left(\mathrm{Fe}_{2} \mathrm{SiO}_{4}\right)$ is synthesized by the reaction of wüstite with quartz. The presence of the wüstite $\left(\mathrm{Fe}_{\mathrm{x}} \mathrm{O}\right)$ as intermediate phase of magnetite reduction at $\mathrm{T}>570^{\circ} \mathrm{C}$ is consistent with thermodynamic predictions given in Figure 4. The complete reduction of $\mathrm{Fe}_{2} \mathrm{SiO}_{4}$ in metallic iron and $\mathrm{SiO}_{2}$ is obtained at $1050^{\circ} \mathrm{C}$.

3. The pellets Reduced pellets Reduced at $\mathrm{T}>1000^{\circ} \mathrm{C}$ contract probably due to the sintering of particles, or to partial melting of some constituents of the pellets. The narrowing of the pellets promotes contact of oxides with reducing agents $\left(\mathrm{C}, \mathrm{CO}, \mathrm{H}_{2}\right)$ improving the reduction process.

4. The reduction of iron oxides, particularly at high temperatures, is carried out by the CO and $\mathrm{H}_{2}$. The carbon monoxide is generated in situ (gasification of carbon by the Boudouard reaction, Figure 4). Hydrogen is also produced during the gasification of carbon by water vapor. The latter comes from the ASR and from the release of structural water from clay during heating.

5. The direct reduction of pellets can be directed using the electric arc furnace for the manufacture of steel.

Considering thermodynamic investigation for a selective extraction of those metals and using an available thermochemical database for the thermodynamic calculation of various Metal-O-Cl systems, a typical example is the predominance area diagram given in Figure 4 for the $(\mathrm{Fe}, \mathrm{Pb})$ $\mathrm{O}-\mathrm{Cl}$ systems at $500{ }^{\circ} \mathrm{C}$. This diagram clearly shows that lead chloride $\left(\mathrm{PbCl}_{2}\right)$ is the most stable phase even for a low partial pressure of chlorine and at high partial pressure of oxygen. By analyzing these results, a large zone (greyish zone in Figure 5) of chlorine and oxygen should be chosen in order to transform lead into $\mathrm{PbCl}_{2}$, while hematite remains intact. Similar 
interpretations are valid for the systems containing zinc and copper. Generally, metal chlorides have lower boiling points compared with their respective sulfides and/or oxides.

As shown in Figure 6, metal chlorides are volatilized at temperatures lower than $1000{ }^{\circ} \mathrm{C}$. This can be suggested that it is possible to achieve a direct reduction of iron oxides into $\mathrm{Fe}^{\circ}$ by ASR and/other plastics and to remove selectively chlorides of tramp elements.
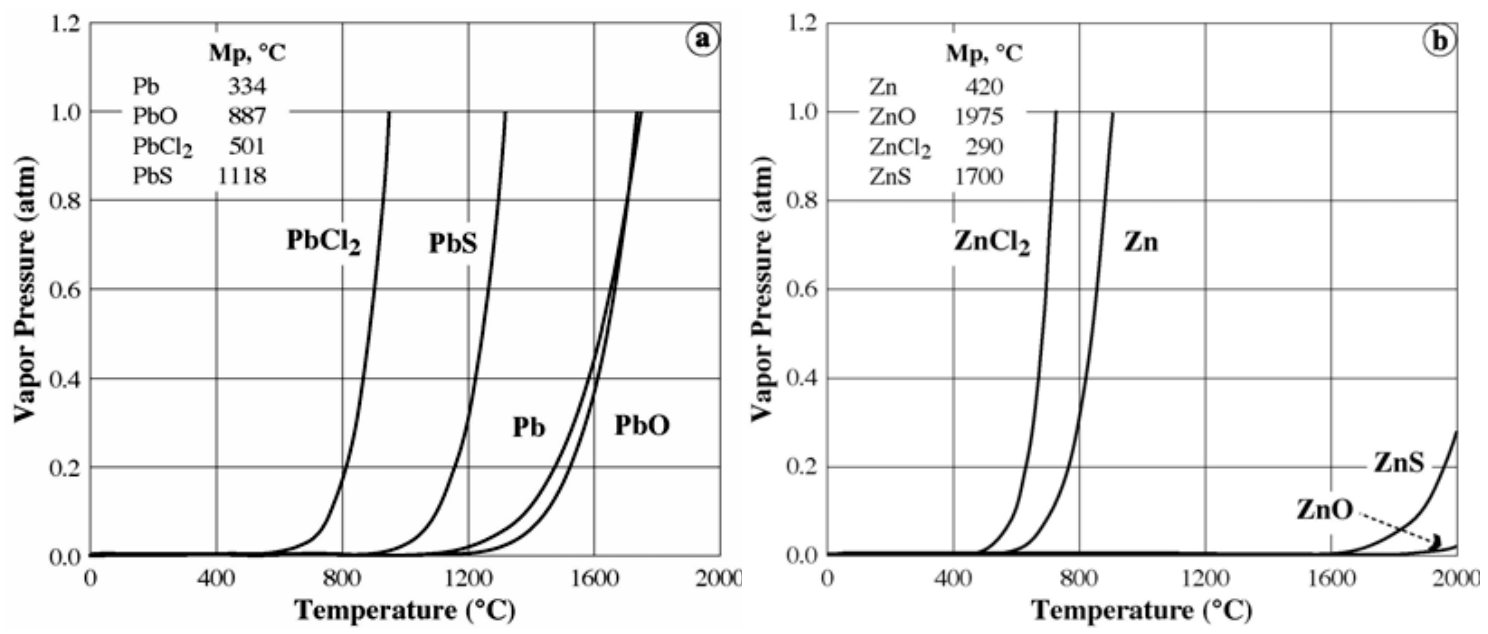

Figure 6: Evolution of vapor pressure of several lead (a) and zinc (b) compounds

\section{Mineral Fractions (MF\#1 and MF\#2)}

The results of size distribution analysis show that most of the materials in MF\#1 and MF\#2 are located in $-2 \mathrm{~mm}$ size classes (Figure 7). $\mathrm{Fe}$ and $\mathrm{Cu}$ in $\mathrm{MF \# 1}$ are concentrated in coarser size classes, while $\mathrm{Fe}$ is homogeneously distributed throughout the classes of MF \#2. Thus, a size cut at $2 \mathrm{~mm}$ will enable to purify this sample from $\mathrm{Cu}$ and to isolate an iron-rich sub-fraction in MF\#1.

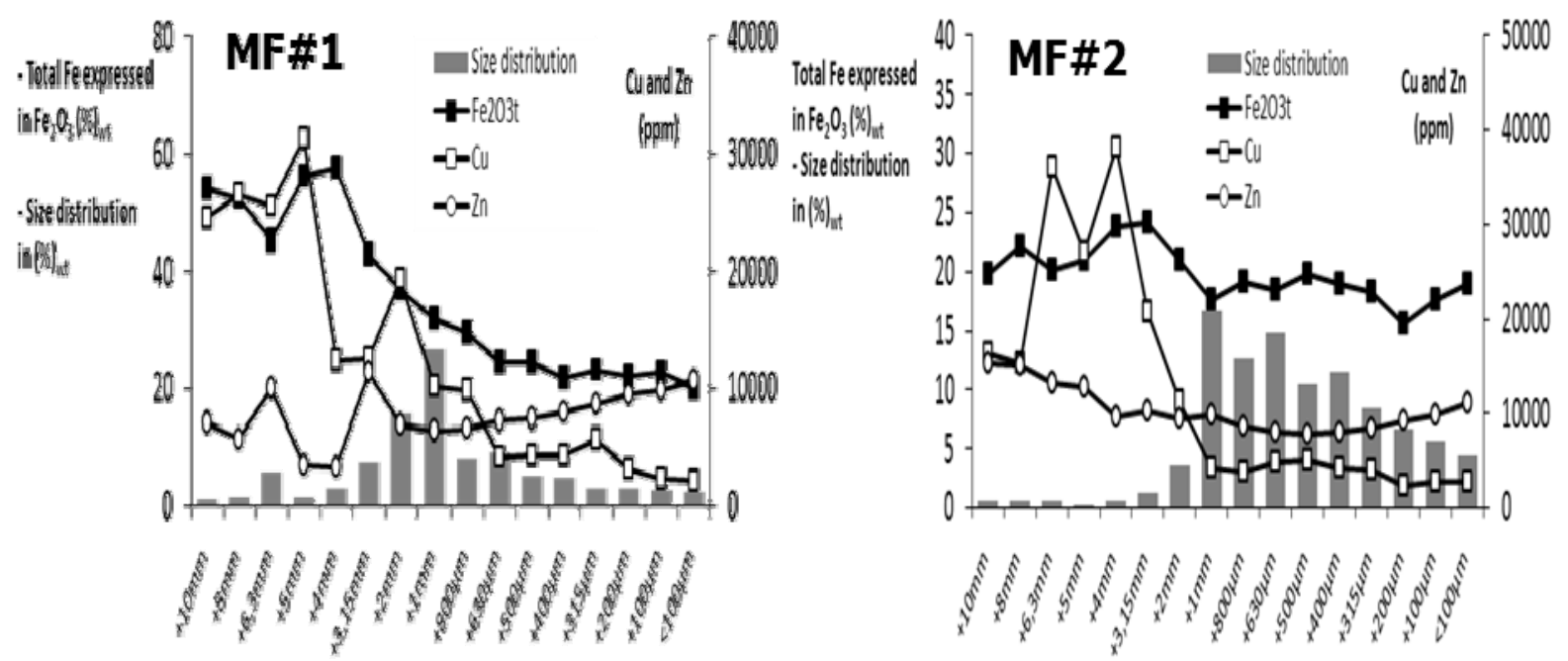

Figure 7: size distributions and $\mathrm{Fe}, \mathrm{Cu}$ and $\mathrm{Zn}$ repartitions in both mineral fractions

Afterwards, a low intensity magnetic separation can be performed to recover magnetic metals. Lastly, considering that some of the smallest materials might be embedded in coarser complex matrixes, the following processes of separation is proposed in this study. This process includes 
sieving step for separate 4 size fraction of $-100 \mu \mathrm{m},-400 / 100 \mu \mathrm{m},-2 / 400 \mu \mathrm{m},-8 / 2 \mu \mathrm{m}$ and $8 \mu \mathrm{m}$. Manual magnetic separation to recover metallic scrap was applied on the fraction $8 \mathrm{~mm}$. The size fractions of $-400 / 100$ and $-2 / 400 \mu \mathrm{m}$ were treated by wet low intensity magnetic separation. Gravity separation using jig process was performed on the fraction $-8 / 2 \mathrm{~mm}$, the products obtained (light and heavy) were treated by magnetic separation. The size fraction of $-100 \mu \mathrm{m}$ was not treated. The products obtained from each operation were analyzed and the results are shown in tables I and II.

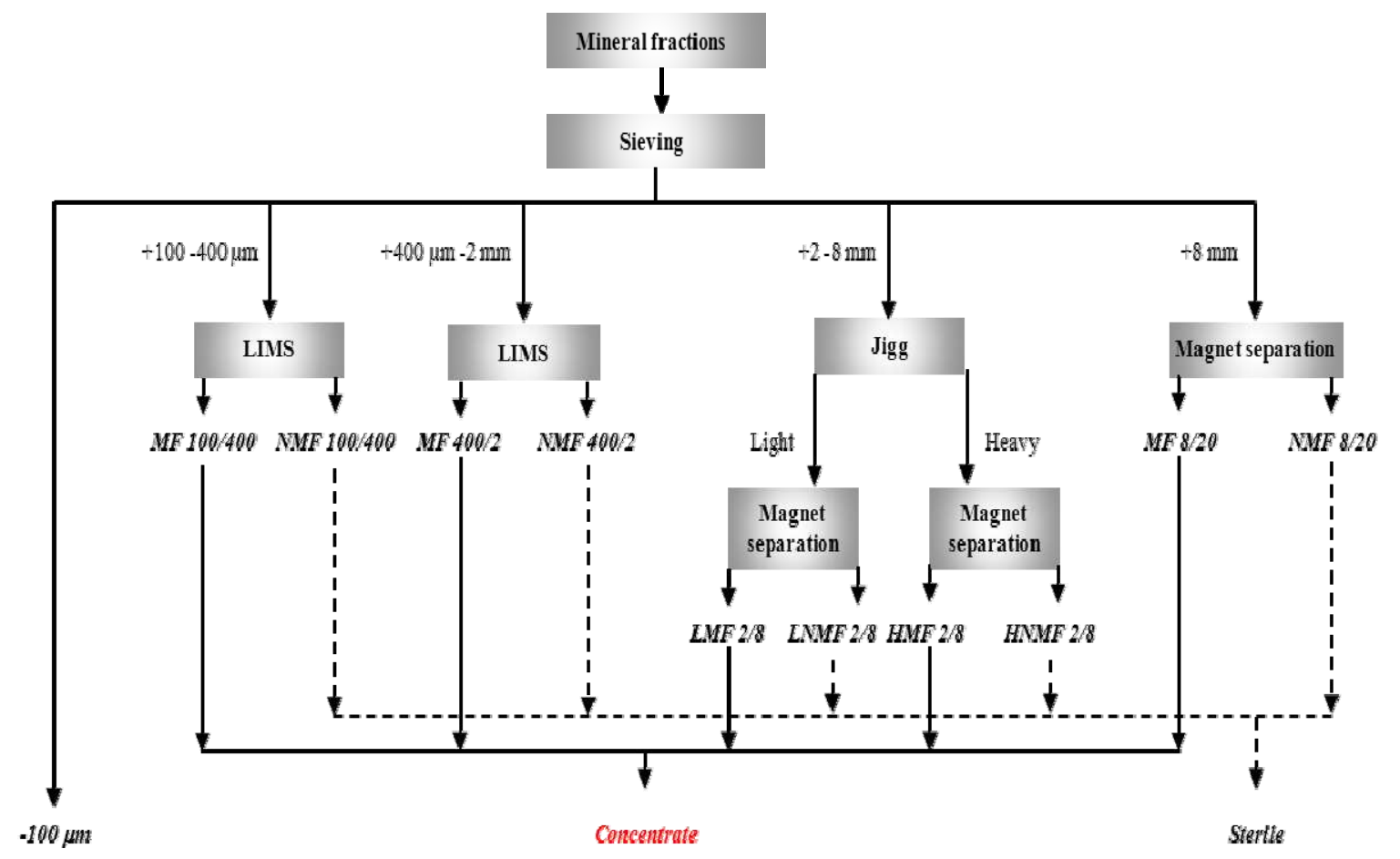

Figure 8: Wet treatment of Mineral fractions (MF\#1 and MF\#2)

Using the process given in Figure 8, it is possible to recover about $79 \%$ of total iron from the fraction MF\#1 with $72.5 \%$ of iron content. However the recovery of iron from MF\#2 is lesser $(62.4 \%)$ with $62 \%$ of iron content. All tramp elements such as $\mathrm{Cu}, \mathrm{Zn}$ and $\mathrm{Pb}$ are more present in the sterile products with high recoveries. The weight $\%$ of $-100 \mu \mathrm{m}$ size fraction for both fractions $\mathrm{MF} \#$ and $\mathrm{MF} \# 2$ are $2.6 \%$ and $5.4 \%$ respectively. These fractions contain very low content of iron (14\% and $13.3 \%)$ and they are not treated in this work.

Table I. Results of wet treatment of MF\#1

\begin{tabular}{|c|c|c|c|c|c|c|c|c|c|c|c|}
\hline Products & $\begin{array}{l}\text { Wt } \\
\% \\
\end{array}$ & $\begin{array}{c}\text { FeOt } \\
\%\end{array}$ & $\begin{array}{c}\rho \mathrm{FeOt} \\
\% \\
\end{array}$ & $\begin{array}{l}\mathrm{Cu} \\
\% \\
\end{array}$ & $\begin{array}{c}\rho \mathrm{Cu} \\
\% \\
\end{array}$ & $\begin{array}{l}\mathrm{Zn} \\
\% \\
\end{array}$ & $\begin{array}{c}\rho Z n \\
\% \\
\end{array}$ & $\begin{array}{l}\mathrm{Pb} \\
\% \\
\end{array}$ & $\begin{array}{c}\rho P b \\
\% \\
\end{array}$ & $\begin{array}{l}\mathrm{Cl} \\
\% \\
\end{array}$ & $\begin{array}{c}\rho C l \\
\%\end{array}$ \\
\hline Concentrate & 36.0 & 72.5 & 79.3 & 0.4 & 11.6 & 0.1 & 22.7 & 0.1 & 11.7 & 0.1 & 16.6 \\
\hline Sterile & 61.4 & 10.5 & 19.6 & 1.6 & 87.9 & 3.6 & 72.6 & 4.9 & 85.5 & 0.3 & 81.9 \\
\hline$-100 \mu \mathrm{m}$ & 2.6 & 14.0 & 1.1 & 0.2 & 0.5 & 0.2 & 4.67 & 0.1 & 2.8 & 2.5 & 1.5 \\
\hline Total & 100.0 & & 100.0 & & 100.0 & & 100.0 & & 100.0 & & 100.0 \\
\hline Reconstituted & & 32.9 & & 1.2 & & 0.5 & & 0.6 & & 0.2 & \\
\hline Analyzed & & 36.8 & & 0.94 & & 0.6 & & 0.5 & & 0.3 & \\
\hline
\end{tabular}


Table II. Results of wet treatment of MF\#2

\begin{tabular}{|c|c|c|c|c|c|c|c|c|c|c|c|}
\hline Products & $\begin{array}{l}\text { Wt } \\
\% \\
\end{array}$ & $\begin{array}{c}\text { FeOt } \\
\%\end{array}$ & $\begin{array}{c}\rho \text { FeOt } \\
\% \\
\end{array}$ & $\begin{array}{c}\mathrm{Cu} \\
\% \\
\end{array}$ & $\begin{array}{c}\rho \mathrm{Cu} \\
\%\end{array}$ & $\begin{array}{l}\mathrm{Zn} \\
\% \\
\end{array}$ & $\begin{array}{c}\rho Z n \\
\% \\
\end{array}$ & $\begin{array}{l}\mathrm{Pb} \\
\% \\
\end{array}$ & $\begin{array}{c}\rho \mathbf{P b} \\
\%\end{array}$ & $\begin{array}{l}\mathrm{Cl} \\
\% \\
\end{array}$ & $\begin{array}{c}\rho \mathrm{Cl} \\
\% \\
\end{array}$ \\
\hline Concentrate & 21.4 & 61.6 & 62.4 & 0.3 & 11.7 & 0.7 & 20.8 & 0.4 & 16.6 & 0.1 & 15.2 \\
\hline Sterile & 73.2 & 8.7 & 33.7 & 0.7 & 86.4 & 0.7 & 71.9 & 0.5 & 75.6 & 0.2 & 79.5 \\
\hline$-100 \mu \mathrm{m}$ & 5.4 & 13.3 & 3.9 & 0.2 & 1.9 & 1.0 & 7.3 & 0.7 & 7.8 & 0.2 & 5.3 \\
\hline Total & 100.0 & & 100.0 & & 100.0 & & 100.0 & & 100.0 & & 100.0 \\
\hline Reconstituted & & 18.8 & & 0.6 & & 0.7 & & 0.5 & & 0.2 & \\
\hline Analysed & & 19.3 & & 0.5 & & 0.9 & & 0.6 & & 0.3 & \\
\hline
\end{tabular}

\section{Evaluation of the Investigated Samples Quality}

The results of calculations using metallurgical model developed by steelmaking industry in France show that the mineral fraction MF\#1 is the closest ore with regards to the iron content. However it is essential to know the nature of the other elements to determine the potential value of this product added to the materials at the agglomeration step before charging into the blast furnaces. Regarding to carbon products, the light plastic fractions (LF) could be more easily valorized in the steel industry, knowing that their major handicap is that they contain volatile carbon while coal or cokes are mainly out of solid carbon. Therefore, valorization channels could focus on:

1. injection into the slag devoted to the electric furnaces to make foam that lead to a better coverage of the electric arc and then improves its thermal performance;

2. addition to the scrap charge to boost the heating of the electric furnace,

3. injection in tuyeres of blast furnaces.

In both the cases (MF\#1 and plastic products), it is essential that the process generating these products, used by many shredders, lead to significant tonnages, since the use of coal for foaming is of the order of $5 \mathrm{~kg} / \mathrm{t}$ of liquid metal for production of electrical steel; what roughly need in France an equivalent of $25 \mathrm{kt}$ of pulverized coal. It must also be considered that the product obtained has a regular composition, what remains to be checked, since the charge of shredders is heterogeneous (ELV, WEEE other equipment). To achieve this goal, it would certainly be needed to go through a stage of homogenization of the products destined to steelmaking industries.

\section{Conclusions}

This work had ambition a multi-parametric analysis of the thermodynamic and experimental use of plastics and automotive shredder residues «ASR» as a substitute of energetic material and reducing agent in metallurgy of iron.

Recycling of ASR is performed at least through two stages: treatment / purification by physical methods followed by an injection of those purified ASR in the furnace. However, the physical methods of extraction of tramp elements $(\mathrm{Cl}, \mathrm{Pb}, \mathrm{Zn}, \mathrm{Cu})$ of ASR strongly depend on their dissemination, their liberation degree as well as their adherence to the matrix that surrounds them. In the absence of a final purification by physical methods, the thermal process developed in this study seems to be quite promising for an alternative process and industrial prospects. We deduced from this thermal approach, that the handicap of coexistence of PVC (source of 
chlorine) and tramp elements $(\mathrm{Pb}, \mathrm{Zn}, \mathrm{Cu})$ can be an asset into respective volatile chlorides at low temperatures. In this context, the future directions of the ASR are:

1. Light plastic fraction can be introduced into the chain of iron ore agglomeration to substitute combustible / reducing materials.

2. The mineral fraction (MF\#1) can also partially substitute for material load for the agglomeration of iron.

3. Material partially reduced by plastic in the form of pellets can be injected into the steel basket.

According to metallurgical operations models, there will be three opportunities to recycle the mineral fractions in the steel industry:

1. by assimilation into the iron load intended for the manufacture of the agglomerate produced which is then loaded to the top of the blast furnaces,

2. by direct charge to the topside

3. by loading to the converter after agglomeration with binders.

The possibilities of valorization of plastic fractions are more numerous, since they can be used as:

1. alternative fuel at the settlement on grid,

2. component of the coke

3. substitute for pulverized coal injected into the tuyeres of blast furnaces,

4. substitute for pulverized coal injected for frothing slag in electric furnaces,

5. substitute for coal brought in the load of scrap in electric furnaces to reduce oxides and bring energy,

6. thermal dopant to converter to increase the sediment charge.

\section{References}

1. Sousanis, J.: "World vehicle population tops 1 billion units, Wards Auto", http://wardsauto.com/ar/world_vehicle_population_110815 (2011). Accessed 25 May 2012

2. Andersen, F., Larsen, H., Skovgaard, M. "Projection of end-of-life vehicles: development of a projection model and estimates for ELVs for 2005-2030". ETC/RWM working paper 2008/2, Copenhagen (2008).

3. Vermeulen, I., Van Caneghem, J., Block, C., Baeyens, J., Vandecasteele, C. “Automotive shredder residue (ASR): reviewing its production from end-of-life vehicles (ELVs) and its recycling, energy or chemicals valorization". J. Haz. Mat, 190 (2011), 8- 27.

4. GHK/BioIS Intelligence Service. "A study to examine the benefits of the End of Life Vehicles Directive"- (Final report to DG Environment, 2006), from:

http://ec.europa.eu/environment/waste/elv_study.htm

5. Directive 2000/53/CE du parlement européen et du conseil du 18 septembre 2000 relative aux véhicules hors d'usage. J. Officiel des Communautés européennes, L 269/34 (2000).

6. Menad, N. "Recycling of auto shredder residue". J. Haz. Mat, A139 (2007), 481 - 490

7. Jalkanen, H. "On the direct recycling of automotive shredder residue and electronic scrap in metallurgical industry”. Acta Metall. Slovaca, 12 (2006), 2625 - 2643. 
8. United Nation Environmental Program (UNEP): Converting waste plastics into a resource compendium of technologies (2010). Available from (accessed on April 10 ${ }^{\text {th }}$ 2012): http://www.unep.or.jp/Ietc/Publications/spc/WastePlasticsEST_Compendium.pdf

9. Kanari, N., Menad, N., Diot, F., Filippov, L., Thomas, F., Yvon, J.: Beneficiation of PVC wastes in iron oxide reduction. Proceedings of the $43^{\text {rd }}$ International October Conference on Mining and Metallurgy, Kladovo, Serbia, 408-411 (2011)

10. Kanari N., Menad N., Diot F., Filippov L., Thomas F., Yvon J. (2012), "Valorization of the automobile shredder residues by thermal route" Proceedings of the $4^{\text {th }}$ International Conference on Engineering for Waste and Biomass Valorization. (WasteEng 2012), September $10^{\text {th }}-13^{\text {th }}$ Porto Portugal. A. Nzihou \& F. Castro eds. Vol 4, 1085-1090. 